\title{
Yeni Gelişmeler Işığında Konjenital Anomalili Böbreklerde Üriner Sistem Taş Hastalığı'nın Tedavisi
}

\author{
Giray Ergin¹, Turgay Ebiloğlu², Yusuf Kibar ${ }^{3}$
}

${ }^{1}$ Ağrı Asker Hastanesi, Üroloji Servisi, Ağı

${ }^{2}$ Etimesgut Asker Hastanesi, Üroloji Servisi, Ankara

${ }^{3}$ Gulhane Askeri Tıp Akademisi, Üroloji Anabilim Dalı, Ankara

\section{Giriş}

$\ddot{U}$ riner sistem anomalili böbreklerde oluşan taşlara yaklaşım ürologlar için özellik arz etmektedir. Çünkü normal anatomiye sahip böbreklerde oluşmuş taşlarda tedavi yaklaşımı belirli iken; anormal anatomideki böbreklerde oluşmuş taşlar için kesinleşmiş bir yaklaşım tarzı bulunmamaktadır. Ekstrakorporeal şok dalga litotripsi (ESWL), üreterorenoskopi (URS), perkütan nefrolitotomi (PCNL), retrograd intrarenal cerrahi (RIRS), minimal invazif PCNL (Mini-Perc), mikroperkütan nefrolitotomi (microperc) gibi yöntemlerin başarı şansı, anatominin farklı oluşu nedeniyle, anomalili böbreklerde meydana gelen taşların tedavisinde normal anatomiye sahip böbreklerdeki kadar yüksek değildir.

Çocuklarda üriner sistem taşı insidansı yaklaşık \%2-3 arasındadır(1). Bu riskin anormal anatomiye sahip böbreklerde oluşan staz sonucu idrarda meydana gelen kristallerin atılımındaki gecikme, enfeksiyon ve yine bu çocuklarda muhtemel var olduğu düşünülen metabolik anomali riskinin yüksekliği nedeni ile arttığı bildirilmektedir (2-4). Ancak üriner sistem anomalilerinin taş oluşum riskini artırıp artırmadığı halen tartışmalıdır (1).

Anormal anatomiye sahip böbreklerdeki taş tedavisinin amacl; tam taş temizliğini sağlamak, yeni taş oluşumunu engellemek veya mevcut küçük parçaların büyümesinin önüne geçmek, üriner sistem enfeksiyonunu önlemek ve renal fonksiyonları korumaktır. Günümüzde anomalili böbreklerde tedavi yaklaşımı gelişen teknoloji ile birlikte hemen hemen normal anatomiye sahip böbreklerdeki gibi planlanıp yapilabilmektedir.

Bu makalenin amacı konjenital anomalili böbreklerde gelişen üriner sistem taşlarında tedavi seçeneklerini yeni ürolojik gelişmeler ışığında incelemektir. Bu amaçla, 1981 ile 2013 yılları arasında konjenital anomalili böbrekler hakkındaki 52 yayin ve olgu bildirimi incelenmiştir.

\section{Üreteropelvik Bileşke Obstrüksiyonu (UPB)}

UPB obstrüksiyonu görülme sıklığı yaklaşık olarak 1250 canlı doğumda 1 olduğu bilinmektedir (3). Bu hastalarda artmış taş oluşum riski için çeşitli hipotezler mevcuttur. Böbrek içerisinde kristal agregatların UPB darlığına bağlı olarak atılımında gecikme olması, üriner enfeksiyonlar ve bu böbrek- lerdeki metabolik bozukluklar suçlanmaktadır $(2,3,5,6)$. Yine bu hastalarda taş oluşum riskinin 70 kat arttığ 1 bildirilmektedir. 15 yaş altı çocuklarda taş oluşma riski $\% 0.035$ olarak bildirilirken, Husmann ve ark.'ları yaptıkları bir çalışmada UPB darlığı olan 15 yaş altı çocuklarda ipsilateral taş riskini \%2.1 olarak bulmuşlardır. Yine bu çalışmada UPB darlık nedeni ile piyeloplasti operasyonu geçiren ürolithiazisli çocuk hastaların takiplerinde \%68 oranında taşın tekrarladığı tespit edilmiştir (3). Bu bulgulara göre anatomik olarak anomalinin cerrahi düzeltilmesinden sonra bile hastalarda taş oluşumu gözlendiği, bu nedenle taş oluşum riski artışının yalnızca staz ve enfeksiyon ile açıklanamayacağı, bunun yanında metabolik anormalliklerin de riski artırdığı sonucuna varılmıştır (3). Cerrahi tedavi sonrası bu hastalarda; sıvı alımının artırılması, diyet ile ilgili önerilerde bulunulması, taşın çıkarılmasından sonraki dönemde antibiyoterapinin 3 ay devamı (sitrüvit taşları için), taş analizine göre spesifik medikal tedavi başlanması ile rekürrens riski azaltılabilmektedir $(3,7)$.

Tekin ve ark.'ları ülkemizde yaptıkları bir çalışmada UPB darlığı olan çocuklarda taş oluşumunda metabolik anomalileri araştırmışlar ve UPB darlığı ile birlikte taşı olan Türk çocuklarında anatomik anomalilerin yanında idrarda kalsiyum, sitrat ve oksalatın anormal atılımının taş oluşum riskini artırdığını bildirmişlerdir (8).

UPB darlığı olan hastalarda geleneksel olarak açık pyeloplasti ve pyelolitotomi operasyonu uygulanmaktadır. Günümüzde gelişen minimal invaziv yaklaşım ile birlikte açlk cerrahiye alternatif olarak PNL beraberinde antegrad endopyelotomi, laparoskopik veya robotik pyeloplasti ve beraberinde fleksible/rijit URS ile taş ekstirpasyonu, PNL ve beraberinde laparoskopik pyeloplasti gibi cerrahi seçenekleri bulunmaktadır. Açı pyeloplasti ve beraberinde pyelolitotomi operasyonunun başarı oranı yaklaşık olarak \%90 ve üzeri olduğu bildirilmektedir. Bunun yanında açı cerrahinin postoperatif dönemde flank insizyonuna bağlı oluşan ağrısı ve uzun dönemde insizyonel herni riski gibi dezavantajları bulunmaktadır $(9,10)$. PNL ve beraberinde antegrad endopyelotomi operasyonunun başarı oranı \%64-85 arası bildirilmektedir $(11,12)$. Endopyelotominin başarı oranının açlk veya laparoskopik pyeloplastiye oranla daha düşük olmasının yanında; renal fonksiyonları kötü olan hastalarda, hidronefroz derecesi yüksek olan hastalarda ve çaprazlayan damar varlığında uygulanamaması temel dezavantajların- 
dandır (13). Laparoskopik veya robotik pyeloplasti ve beraberinde fleksible/rijit üreterorenoskopi ile taş ekstirpasyonu için yalnızca laparoskopik pyeloplastinin başarı oranı \%96 olarak rapor edilmektedir (14). Laparoskopik pyeloplasti ve beraberinde yapılan pyelolitotomide taşsızlık oranları ise fleksible renoskopların kullanımı ile birlikte \%80-90 arası olduğu bildirilmektedir (15-17). Bu yöntemde floroskopi ve litotriptör olmadan taşlar fleksible veya rijit renoskop ile nitinol basket kullanılarak alınmaktadır. Bu nedenle taş sayısı az olan ve yaklaşık 5-20 mm boyutları arası taşlarda tercih edilmesi gerektiği bildirilmektedir. Diğer bir sıkıntı taşların batın içine kaçabilmesi, rezidüel taş kalma riski ve fleksible aletlerin kullanımının nispeten zor oluşudur (15-17). PNL ve beraberinde laparoskopik pyeloplasti operasyonunda, laparoskopik pyeloplasti ve beraberinde taşın fleksible veya rijid renoskop kullanılarak basket katater ile çıkarılmasına göre, intraoperatif floroskopinin ve litotriptörlerin kullanımının mümkün olması nedeni ile taşsızlık oranları \%100'e yakındır. Floroskopi ve litotriptörlerin intraoperatif kullanım imkanı nedeni ile bu vakalarda taşın sayısı, boyutu kısıtlayıcı değil$\operatorname{dir}(18)$.

\section{At Nalı Böbrek Anomalisi}

En sık görülen renal füzyon anomalisi olan at nalı böbreğin prevelansı \%0.25 civarında olduğu bildirilmekte ve at nalı böbrek anomalisinin erkeklerde görülme sıklığı kızlarda ki görülme sıklığının yaklaşık 2 katı olduğu bilinmektedir $(19,20)$. Füze olmuş böbrek daha kaudalde yerleşir ve rotasyon defektine bağlı olarak tüm kaliksler ve renal pelvis anterior yerleşimli olur. Malrote füze olmuş böbrek nedeni ile üreter renal pelvis birleşimi normalden daha süperiorda ve lateralde gerçekleşir (yüksek insersiyon) (21). Bu anomalilere bağlı olarak böbreklerde üriner drenaj bozulur ve staz meydana gelir. Oluşan staz sonucu taş oluşma olasılığı artar. At nalı böbreklerde taş oluşma riskinin \%20'den daha fazla olduğu bilinmektedir. At nalı böbreğin innervasyonu normal anatomiye sahip böbrekler ile aynı olduğu için semptomatolojisi benzerdir. Bunun yanı sıra at nalı böbreklerin anormal vasküler komşulukları ve anatomisi değişmiş yapıları tedavi seçimi sırasında önem arz etmektedirler. UPB obstrüksiyonunun varlığı tedavinin başarısını ciddi ölçüde etkileyebileceği için seçilen tedavi öncesinde tedavi alternatifleri mutlaka detaylı olarak değerlendirilmelidir. ESWL, URS, PCNL, laparoskopik ve açık cerrahi yaklaşımlar tedavi seçenekleri içerisinde yer almaktadır.

ESWL, at nalı böbreklerde kullanılan en minimal invaziv tedavi yöntemidir. Fragmantasyon ve taşsızlık oranları sırası ile \%80, \%28-\%80 arası olduğu bildirilmektedir (2224). Başarının yüksek olarak sunulduğu çalışmalarda çok sayıda ESWL seansı veya ek girişimler olduğu ve $4 \mathrm{~mm}$ 'den küçük olan rezidü fragmanların başarı olarak kabul edildiği görülmektedir. ESWL başarısının at nalı böbreklerde normal anatomiye sahip böbreklerdekinden daha az olmasına neden olan birçok faktör mevcuttur. Üriner staz, toplayıcı sistemdeki dilatasyon ve üreterin renal pelvise yüksek girişi fragmente parçaların atılmasını zorlaştırmaktadır. Bu nedenle taşın lokalizasyonu ve taş yükü at nalı böbreklerde taşsızlık oranlarını anlamlı düzeyde etkilemektedir. ESWL'nin başarısını etkileyen faktörlerden biri taş boyutudur. Sheir ve ark.'ları'nın yaptığı çalışmada 15 mm'den küçük taşlarda başarı oranı \%79 olarak bildirilirken, taş boyutu $15 \mathrm{~mm}$ 'den büyük taşlarda başarı oranın \%53 olarak rapor edilmektedir (25). Bu nedenle Clayman ve ark.'ları taşsızlık oranı daha yüksek olduğu için 10-15 mm'den büyük taşlarda PCNL uygulanmasını önermektedirler (26). Yine Ray ve ark.'larının yaptığ1 ve bu konudaki en geniş serilerden biri olan çalışmada, yazarlar 41 atnalı böbrekli hastaya ESWL uygulamışlardır. Sonuç olarak tek seans ile başarının \%25 ve tam taş temizlik oranının \%9.1 olduğunu bildirmişlerdir. Genel başarı oranını \%63.6, genel taşsızlık oranını ise \%39.1 olarak tespit etmişlerdir. Bu hastaların \%73'ü tekrarlayan ESWL seansı, PCNL, URS gibi ek tedavi modalitelerine ihtiyaç duymuşlardır (27). Böbrek taşlarının ultrasonografik olarak lokalizasyonu, bu hastalarda böbreklerin daha mediale yerleşimi nedeni ile çok efektif değildir. Floroskopik odaklama durumunda taş vertebraların spinöz çıkıntılarına veya kemik pelvise süperpoze olup net olarak odaklanamayabilir. Bu nedenlerle at nalı böbrekli hastalara ESWL uygulanması durumunda hastaların flank veya supin pozisyonunda ESWL masasına yatırılması taşların süperpoze olmasını engelleyip, floroskopi ile daha net görüntü alınmasına ve böylece litotriptörün odaklanmasına olanak sağlamaktadır.

At nalı böbrek üreterlerinin tortioze oluşu ve proksimal kısımlarının isthmus üzerinden geçmesi nedeni ile semirijit URS kullanımı at nalı böbrekli hastaların proksimal üreter taşlarında tehlikelidir. Fleksible URS, lazer litotriptörler ve nitinol basket kateter kullanımının ortaya çıkması ile kalisiyel taşlarda kullanılmaya başlanmıştır. Feksibl üreterorenoskopi; ESWL veya PCNL uygulamasının sakıncalı olduğu at nalı böbrekli hastalarda kullanılabilecek iyi bir alternatif tedavi yöntemidir (28). Flexible URS'larin günümüzde gelişen teknoloji ile birlikte çapları küçülmüş, çalışma kanalları genişlemiş, beraberinde kullanılan lazer, basket kateter gibi araçların sayısı ve çeşidi artmıştır. Yine bu aletlere ulaşım giderek artmaktadır. Tüm bu sebeplerle at nalı böbrekli hastalarda taş tedavisi için flexible URS'larin kullanım alanı giderek artmaktadır. Atış ve ark.'larının yaptığı bir çalışmada flexible URS'nin başarı oranı \%70 olarak rapor edilmiştir. Geri kalan \%30'luk başarısız operasyonların \%71'inin alt pol taşı olduğu ve aynı zamanda $22 \mathrm{~mm}$ 'den büyük taşlar olduğu bildirilmiştir (29).

Perkütan nefrolitotomi'de at nalı böbrekler için taşsızlık oranları yaklaşık \%75 olarak bildirilmektedir (19, 30). ESWL'den fayda görmemiş $2 \mathrm{~cm}$ 'den büyük taşlarda standart tedavi yöntemi günümüzde PCNL olarak kabul edilmektedir $(31,32)$. PCNL için at nalı böbreklere en iyi giriş yerinin genellikle üst pol-posterior kaliks olduğu söylenmektedir (30). Bu giriş ile doğrudan renal pelvise ulaşım sağlanır ve daha az pnömotoraks riski vardır. Dezavantaj olarak at nalı böbreklerin normal böbreklere göre manipulasyona açık olmaları nedeniyle tam taş temizliği için bu hastalarda birden çok perkütan giriş gerekebilmektedir (19). Yine at nalı böbreklerin daha anterior yerleşimli olmaları sebebiyle retro renal kolon bulunma riski de daha yüksektir. Kolon ve diğer komşu organlarla, major vasküler hasar riskini en aza düşürmek için preoperatif dönemde bu hastaların BT ile değerlendirilmesi önerilmektedir (30). Ek olarak at nalı böbreğin daha kaudal yerleşimi nedeni ile; interkostal perkütan girişlerde pulmoner yaralanma oranları normal anatomiye sahip böbreklere göre daha düşük olduğu bilinmektedir $(19,30)$.

At nalı böbreklerde taşa laparoskopik yaklaşım renal pelvisin anterior yerleşimli olması nedeni ile uygulanabilir ve güvenli bir tedavi seçeneği olarak bilinmektedir. Beraberinde 
UPJ darlığı olan vakalarda eş zamanlı pyeloplasti operasyonuna imkân sağlaması laparoskopinin ayrıcalıklarından biridir. Ayrıca daha fazla anatomik anomalisi veya yüksek komşu organ veya damar yaralanması riski olan vakalarda laparoskopi yardımı ile böbreğe PCNL için doğrudan görüş altında giriş yapılabilir (33).

\section{Pelvik Böbrek}

Bir renal çıkış anomalisi olan pelvik böbreğin yaklaşık insidans1 2100-3000'de 1 olarak bilinmekte ve sol böbreğin daha sık etkilendiği belirtilmektedir $(34,35)$. Pelvik böbrekler genelde semptom vermezler ve insidental olarak tespit edilirler. Bu böbrekler sıklıkla malrote ve yüksek insersiyona sahip üretere sahiptirler. Bu da; böbrekte üriner staza ve dolayısıyla taş formasyonuna yol açan bir predispozan bir faktördür. (36). Pelvik böbrekteki taşa yaklaşım, at nalı böbrekteki taşa yaklaşımla benzerdir.

ESWL ile ultrasonik olarak pelvik böbrekteki taşı odaklama şansı kemik pelvis nedeni ile oldukça düşüktür. Ancak anterior'dan şok dalgaları taşa ulaşabilir $(37,38)$. Bu nedenle ESWL anterior yaklaşımla uygulanmalıdır. Komşu organ yaralanma riskini en aza indirmek için işlem öncesi BT ile komşu bağırsaklar ve böbreğin anatomisi belirlenebilir. Pelvik böbrekte ESWL ile taşsızlık oranları \%25-92 arası bildirilmektedir $(15,39)$. Ancak yüksek taşsızlık oranlarının bildirildiği çoğu çalışmada ESWL sonrası tekrar ESWL, URS, D-J stent yerleştirilmesi gibi birçok ek girişimin uygulandığ görülmektedir (39).

Günümüzde pelvik ektopik böbreklerde URS, yeni geliştirilen ve daha fazla bükülebilir üreterorenoskoplar ve daha küçük enstrumanlar sayesinde ESWL'ye alternatif bir tedavi yöntemi haline gelmektedir (28). Pelvik ektopik böbreklerde üreterorenoskopik girişimlerde gelişen teknoloji sayesinde taşsızlık oranları \%80'ler civarında bildirilmektedir (28). URS ile ESWL'nin aksine tek seansta yüksek taşsızlık oranı sağlanabilirken, ESWL'de bu taşsızlık oranını sağlayabilmek için ek girişimlerin gerektiği görülmektedir.

PCNL abdominal organ ve damar yaralanma riski yüksekliği nedeni ile pelvik ektopik taşlı böbrekler için önerilen bir tedavi yöntemi değildir.

Günümüzde laparoskopik girişimlerin yaygınlaşması ve teknolojik gelişmeler ile birlikte; pelvik ektopik böbreğe direk laparoskopik görüş altında giriş sağlanmakta ve böylece litotripsi veya litotomi işlemi gerçekleştirilmektedir. Literatürde bu yöntem ile ilgili olarak taşsızlık oranları yüksek, komplikasyon oranlarının düşük olduğu bildirilmektedir (34). Robotik cerrahinin günümüzde hızla yaygınlaşması ile literatürde UPJ darlığının eşlik ettiği birçok pelvik ektopik taşlı böbrek vakasında robotik pyelolitotomi ve beraberinde pyeloplasti operasyonu bildirilmiştir. Bu vakalarda taşsızlık oranları \%80-100 arasında olduğu bildirilmektedir.

Pelvik ektopik taşlı böbreklerde laparoskopik yaklaşım ile pyeleolitotomi operasyonunun, trokar içerisinden aynı zamanda fleksible sistoskop veya renoskopun kullanilabilme şansı nedeni ile kullanımı yaygınlaşmaktadır. Özellikle UPJ darlığ da olan pelvik böbrek içerisindeki taşların tedavisinde laparoskopik/robotik yaklaşım önerilmektedir. Taşsızlık oranları bu yöntemde \%80-100 arası bildirilmektedir (15).

Pelvik böbrekte taş tedavisi özetle; UPJ darlığın ekarte edildiği vakalarda taş eğer $2 \mathrm{~cm}$ 'den küçük ise ESWL veya URS ilk tedavi seçenekleri olarak değerlendirilmekteyken, 2 cm'den büyük taşlarda ve UPJ darlığın eşlik ettiği vakalarda PCNL veya laparoskopik tedavinin ilk tedavi yaklaşımı olarak uygulanması önerilmektedir (20).

Microperc uygulamaları da; ektopik böbrekteki taşların tedavisinde yerini almaktadır. US yardımlı microperc girişlerinin yaygınlaştığını söylemek gerekirken; laparoskopi yardımlı microperc uygulamalarının kolaylığını gösteren olgu sunumları literatürde yerini almaya başlamıştır $(40,41)$.

\section{Çapraz Renal Ektopi}

Çapraz renal ektopinin insidansı yaklaşık 1000'de 1 olarak bildirilmektedir (35). Çapraz renal ektopili böbrek taşlarında tedavi yaklaşımı temelde normal böbreklerdeki gibidir. Ancak çapraz renal ektopili böbreklerde taş tedavisinde seçilecek cerrahi yaklaşıma karar vermek için BT ile hastanın renal anatomisinin iyi değerlendirilmesi, beraberinde ek anomalinin olup olmadığının tespit edilmesi önemlidir. Modi ve ark.'ları çapraz renal ektopisi, taşı ve UPJ darlığı olan bir pediatrik vakada yaptıkları transperitoneal laparoskopik pyelolitotomi ve pyeloplasti vakasında tam taşsızlık rapor etmişlerdir (42). Çapraz renal ektopide taşa yaklaşım için laparoskopinin yanında diğer tedavi modaliteleri uygun vakalarda URS ve ESWL'dir.

\section{Vezikoüreteral Reflü (VUR)}

VUR'lu çocuklarda taş insidansı yaklaşık \%8-18 arasında bildirilmektedir. Fizyopatolojide reflüye bağlı staz, enfeksiyon ve metabolik anormallikler suçlanmaktadır $(43,44)$. VUR'lu çocuklarda hiperkalsiüri ve hiperürikozüri görülme sıklığı sağlıklı çocuklara göre daha yüksek oranda olduğu tespit edilmiştir (\%18.7-\%21.3) $(43,44)$. Bu hasta grubunda üriner sistem taş hastalığına yaklaşımın prensipleri, nonreflüksif hastalara benzerdir.

\section{Otozomal Dominant Polikistik Böbrek Hastalığı (ODPKBH)}

ODPKBH en sık rastlanan herediter böbrek hastalığıdır ve 500-1000 canlı doğumda bir görülmektedir (45). Üriner sistem taş hastalığı'nın ODPKBH'larında genel popülasyona göre 5-10 kat daha fazla olduğu bilinmektedir (46). Taş görülme riskinin artmış olması hem anatomik, hem de metabolik sebeplere bağlıdır. İdrar akımının büyümüş kistler nedeni ile zayıf olması sonucu gelişen idrar stazı, anatomik taş oluşum riskini oluştururken; metabolik olarak idrar $\mathrm{pH}^{\prime}$ sının, idrar sitrat ve magnezyum düzeylerinin ODPKBH'larında düşük olmasının taş oluşum sebebi olduğu düşünülmektedir $(47,48)$. BT bu hastalarda tedavi seçimi için önemlidir.

Taşın pozisyonu ve taşın büyüklüğü bu hastalarda ESWL kararı verilmesinde oldukça etkili olmasına rağmen; ESWL başarısı bu hastalar için \%25 gibi düşük bir oranda bildirilmiştir (49).

ODPKBH'larında URS kullanımı ile ilgili birkaç literatür mevcuttur. Liu ve ark.'larının 13 olguluk serisinde taşsızlık oranının ilk fleksible URS de \%84.5, ikinci URS'de \%92.3 olduğunu bildirilmiştir (50). Literatürlere bakıldığında üreterorenoskopinin ODPKBH'da 2' $\mathrm{cm}$ den daha küçük boyutlu taşlarda tercih edilebilir bir yöntem olduğu görülmektedir.

PCNL seçiminde zorluk bu hastalarda ilk girişte kist içine veya toplayıcı sisteme girilip girilmediğinin anlaşılmasıdır. 
Toplayıcı sisteme girildiğini doğrulamak için kullanılan bir yöntem retrograd olarak toplayıcı sistemin metilen mavisi ile doldurulmasıdır. Bu sayede iğne ile giriş sonrası yapılan aspirasyonda metilen mavisinin geldiğini görmek toplayıc1 sisteme girildiğinin bir kanıtı olarak değerlendirilebilir. Al-Kandari ve ark.'larının 20 hasta ile yaptığ 1 ve Srivastava ve ark.'larının 22 hasta ile yaptığı literatürdeki en fazla vaka sayılı iki seride, PCNL başarı oranları \%89.4 ve \%88 olarak rapor edilmiştir $(51,52)$.

Özetle, ODPKBH'nda $2 \mathrm{~cm}$ den küçük taşlar için URS ve ESWL en iyi tedavi yaklaşımı iken; 2 cm'den büyük taşlar için PCNL daha iyi bir tedavi yaklaşımı olabilir.

\section{Kaynaklar}

1. Gupta, M. and M.W. Lee (2007) Treatment of stones associated with complex or anomalous renal anatomy. Urol Clin North Am 34: 431-41.

2. Rutchik, S.D. and M.I. Resnick (1998) Ureteropelvic junction obstruction and renal calculi. Pathophysiology and implications for management. Urol Clin North Am 25: 317-21.

3. Husmann, D.A., D.S. Milliner, and J.W. Segura (1996) Ureteropelvic junction obstruction with concurrent renal pelvic calculi in the pediatric patient: a long-term followup. J Urol 156: 741-3.

4. Hsu, T.H. and S.B. Streem (1998) Metabolic abnormalities in patients with caliceal diverticular calculi. J Urol 160: 1640-2.

5. Burns, J.R., B. Finlayson, and J. Gauthier (1984) Calcium oxalate retention in subjects with crystalluria. Urol Int 39: 36-9.

6. Jenkins, A.D., Calculus formation, in Adult and pediatric urology, $4^{\text {th }}$ Edition. Editor: McLaughlin M.A. Philadelphia USA, Lippincott Williams \& Wilkins, 2002; 355-393.

7. Hosking, D.H., S.B. Erickson, C.J. Van den Berg, et al. (1983) The stone clinic effect in patients with idiopathic calcium urolithiasis. J Urol 130: 1115-8.

8. Tekin, A., S. Tekgul, N. Atsu, et al. (2001) Ureteropelvic junction obstruction and coexisting renal calculi in children: role of metabolic abnormalities. Urology 57: 542-5; discussion 545-6.

9. Arun, N., N.S. Kekre, V. Nath, et al. (1997) Is open pyeloplasty still justified? Br J Urol 80: 379-81.

10. O'Reilly, P.H., P.J. Brooman, S. Mak, et al. (2001) The long-term results of Anderson-Hynes pyeloplasty. BJU Int 87: 287-9.

11. Cassis, A.N., G.E. Brannen, W.H. Bush, et al. (1991) Endopyelotomy: review of results and complications. J Urol 146: 1492-5.

12. Motola, J.A., G.H. Badlani, and A.D. Smith (1993) Results of 212 consecutive endopyelotomies: an 8-year followup. J Urol 149: 453-6.

13. Knudsen, B.E., A.J. Cook, J.D. Watterson, et al. (2004) Percutaneous antegrade endopyelotomy: long-term results from one institution. Urology 63: 230-4.

14. Moon, D.A., M.A. El-Shazly, C.M. Chang, et al. (2006) Laparoscopic pyeloplasty: evolution of a new gold standard. Urology 67: 932-6.

15. Ramakumar, S., V. Lancini, D.Y. Chan, et al. (2002) Laparoscopic pyeloplasty with concomitant pyelolithotomy. J Urol 167: 1378-80.

16. Ball, A.J., R.J. Leveillee, V.R. Patel, et al. (2004) Laparoscopic pyeloplasty and flexible nephroscopy: simultaneous treatment of ureteropelvic junction obstruction and nephrolithiasis. JSLS 8: 223-8.

17. Whelan, J.P. and J.D. Wiesenthal (2004) Laparoscopic pyeloplasty with simultaneous pyelolithotomy using a flexible ureteroscope. Can J Urol 11: 2207-9.

18. Agarwal, A., A. Varshney, and B.S. Bansal (2008) Concomitant percutaneous nephrolithotomy and transperitoneal laparoscopic pyeloplasty for ureteropelvic junction obstruction complicated by stones. J Endourol 22: 2251-5.

19. Raj, G.V., B.K. Auge, A.Z. Weizer, et al. (2003) Percutaneous management of calculi within horseshoe kidneys. J Urol 170: 48-51.

20. Tan, Y.K., D.Y. Cha, and M. Gupta (2013) Management of stones in abnormal situations. Urol Clin North Am 40: 79-97.

21. Esuvaranathan, K., E.C. Tan, K.H. Tung, et al. (1991) Stones in horseshoe kidneys: results of treatment by extracorporeal shock wave lithotripsy and endourology. J Urol 146: 1213-5.

22. Chen, W.C., Y.H. Lee, J.K. Huang, et al. (1993) Experience using extracorporeal shock-wave lithotripsy to treat urinary calculi in problem kidneys. Urol Int 51: 32-8.

23. Smith, J.E., K.N. Van Arsdalen, P.M. Hanno, et al. (1989) Extracorporeal shock wave lithotripsy treatment of calculi in horseshoe kidneys. J Urol 142: 683-6.

24. Kirkali, Z., A.A. Esen, and M.U. Mungan (1996) Effectiveness of extracorporeal shockwave lithotripsy in the management of stone-bearing horseshoe kidneys. J Endourol 10: 13-5.

25. Sheir, K.Z., K. Madbouly, E. Elsobky, et al. (2003) Extracorporeal shock wave lithotripsy in anomalous kidneys: 11-year experience with two second-generation lithotripters. Urology 62: 10-5; discussion 15-6.

26. Clayman, R.V. (1998) Effectiveness of extracorporeal shockwave lithotripsy in the management of stonebearing horseshoe kidneys. J Urol 160: 1949.

27. Ray, A.A., D. Ghiculete, D.A.H. RJ, et al. (2011) Shockwave lithotripsy in patients with horseshoe kidney: determinants of success. J Endourol 25: 487-93.

28. Weizer, A.Z., W.P. Springhart, W.O. Ekeruo, et al. (2005) Ureteroscopic management of renal calculi in anomalous kidneys. Urology 65: 265-9.

29. Atis, G., B. Resorlu, C. Gurbuz, et al. (2013) Retrograde intrarenal surgery in patients with horseshoe kidneys. Urolithiasis 41: 79-83.

30. Shokeir, A.A., A.R. El-Nahas, A.M. Shoma, et al. (2004) Percutaneous nephrolithotomy in treatment of large stones within horseshoe kidneys. Urology 64: 426-9.

31. Wickham, J.E. and M.J. Kellett (1981) Percutaneous nephrolithotomy. Br J Urol 53: 297-9.

32. Clayman, R.V., V. Surya, R.P. Miller, et al. (1983) Percutaneous nephrolithotomy. An approach to branched and staghorn renal calculi. JAMA 250: 73-5.

33. Maheshwari, P.N., D.S. Bhandarkar, R.S. Shah, et al. (2004) Laparoscopy-assisted transperitoneal percutaneous nephrolithotomy for recurrent calculus in isthmic calix of horseshoe kidney. J Endourol 18: 858-61.

34. Zafar, F.S. and J.E. Lingeman (1996) Value of laparoscopy 
in the management of calculi complicating renal malformations. J Endourol 10: 379-83.

35. Shapiro E., Stuart B., Chow JS. Anomalies of the upper urinary tract. Campbell-Walsh Urology, 10th Edition. Editör: Wein AJ, Kavoussi L, Partin AW, Novick AC, Peters CA. Philadelphia USA, Elsevier Saunders, 2012; 3123-3160

36. Gleason, P.E., P.P. Kelalis, D.A. Husmann, et al. (1994) Hydronephrosis in renal ectopia: incidence, etiology and significance. J Urol 151: 1660-1.

37. Baltaci, S., K. Sarica, E. Ozdiler, et al. (1994) Extracorporeal shockwave lithotripsy in anomalous kidneys. J Endourol 8: 179-81.

38. Talic, R.F. (1996) Extracorporeal shock-wave lithotripsy monotherapy in renal pelvic ectopia. Urology 48: 857-61.

39. Rigatti, P., F. Montorsi, G. Guazzoni, et al. (1991) Multimodal therapy for stones in pelvic kidneys. Urol Int 46: 29-34.

40. Tepeler, A., M.S. Silay, A. Armagan, et al. (2013) Laparoscopic-assisted "microperc" of a stone in a pelvic kidney of a 3-year-old girl. J Laparoendosc Adv Surg Tech A 23: 174-6.

41. Ganesamoni, R., R.B. Sabnis, S. Mishra, et al. (2013) Microperc for the management of renal calculi in pelvic ectopic kidneys. Indian J Urol 29: 257-9.

42. Modi, P., R. Goel, and S. Dodia (2006) Case report: laparoscopic pyeloplasty with pyelolithotomy in crossed fused ectopia. J Endourol 20: 191-3.

43. Rizvi, S.A., S.A. Naqvi, Z. Hussain, et al. (2002) Pediatric urolithiasis: developing nation perspectives. J Urol 168: 1522-5.

44. Noe, H.N., F.B. Stapleton, G.R. Jerkins, et al. (1983) Clinical experience with pediatric urolithiasis. J Urol 129: 1166-8.

45. Mufti, U.B. and S.K. Nalagatla (2010) Nephrolithiasis in autosomal dominant polycystic kidney disease. J Endourol 24: 1557-61.

46. Delaney, V.B., S. Adler, F.J. Bruns, et al. (1985) Autosomal dominant polycystic kidney disease: presentation, complications, and prognosis. Am J Kidney Dis 5: 104-11.

47. Grampsas, S.A., P.S. Chandhoke, J. Fan, et al. (2000) Anatomic and metabolic risk factors for nephrolithiasis in patients with autosomal dominant polycystic kidney disease. Am J Kidney Dis 36: 53-7.

48. Torres, V.E., D.M. Wilson, R.R. Hattery, et al. (1993) Renal stone disease in autosomal dominant polycystic kidney disease. Am J Kidney Dis 22: 513-9.

49. Deliveliotis, C., V. Argiropoulos, J. Varkarakis, et al. (2002) Extracorporeal shock wave lithotripsy produces a lower stone-free rate in patients with stones and renal cysts. Int J Urol 9: 11-4.

50. Yili, L., L. Yongzhi, L. Ning, et al. (2012) Flexible ureteroscopy and holmium laser lithotripsy for treatment of upper urinary tract calculi in patients with autosomal dominant polycystic kidney disease. Urol Res 40: 87-91.

51. Al-Kandari, A.M., A.M. Shoma, I. Eraky, et al. (2009) Percutaneous nephrolithotomy for management of upper urinary tract calculi in patients with autosomal dominant polycystic kidney disease. Urology 74: 273-7.

52. Srivastava, A., R. Bansal, A. Srivastava, et al. (2012) Percutaneous nephrolithotomy in polycystic kidney disease: is it safe and effective? Int Urol Nephrol 44: 72530 .

Yazışma Adresi:

Giray Ergin,

Ağrn Asker Hastanesi, Üroloji Servisi, A ̆grn

Tel: +90 5323063959

e-mail:drgirayergin@gmail.com 